\title{
Inovação na gestão pública subnacional: reflexões sobre a estratégia de desenvolvimento do Acre
}

\author{
Markus Erwin Brose \\ Pesquisador independente
}

\begin{abstract}
Revisões periódicas das tendências da inovação na gestão pública subnacional desde a redemocratização reiteram a necessidade de ampliação dos estudos nesta área. Além dessa demanda por estudos quanto a novos serviços, procedimentos inovadores e modernização da gestão, o presente artigo busca reforçar a necessidade de estudos sobre a qualidade da governança. Utilizamos para tanto a descrição da estratégia de desenvolvimento do Acre como estudo de caso, evidenciando o papel relevante da gestão pública na melhoria da qualidade de vida naquele estado, e sua preparação aos impactos das mudanças climáticas. A análise permite refletir sobre a importância do contexto político e social do qual surgem inovações, para além da replicação de receituários, sendo a gestão de conhecimento indutora a inovações.
\end{abstract}

Palavras-chave: inovação; inclusão social; adaptação a mudanças climáticas; Acre.

Innovación en la gestión pública subnacional: reflexiones sobre la estrategia de desarrollo de Acre

Revisiones periódicas de la innovación en la administración pública sub-nacional desde la democratización reiteraron la necesidad de realizar más estudios en esta área. Además de la demanda de estudios sobre nuevos servicios, procedimientos innovadores y de modernización de la gestión, el artículo tiene por objeto reforzar la necesidad de estudios sobre la calidad del gobierno. Se utiliza tanto para la descripción de la estrategia de desarrollo de Acre como caso de estudio, con el objetivo de destacar el papel de la gestión pública en la mejora de la calidad de vida en ese estado, y su preparación para los impactos del cambio climático. El análisis nos permite reflexionar sobre la importancia del contexto político y social para las innovaciones que se producen más allá de la repetición de recetas.

Palabras clave: innovación; inclusión social; adaptación al cambio climático; Acre.

Innovation in sub-national public management: an analysis of the development strategy of Acre

Periodic reviews about trends of innovation in subnational public administration since democratization reiterated the need for further studies in this area. Besides the demand for studies on new services,

http://dx.doi.org/10.1590/0034-76121601

Artigo recebido em 12 jun. 2013 e aceito em 29 nov. 2013.

Rev. Adm. Pública - Rio de Janeiro 48(2):277-294, mar./abr. 2014 
innovative procedures and management modernization, this article seeks to reinforce the need for studies on the quality of governance. We present a description of the development strategy of Acre as a case study, aiming to highlight the role of public management in improving the quality of life in that state, and its adaptation to climate change impacts. The analysis allows us to reflect on the importance of the political and social context for innovations which arise beyond the replication of prescriptions, the habit of knowledge management being conductive to innovation.

Keywords: innovation; social inclusion; climate change adaptation; Acre.

\section{Introdução}

Em revisão das tendências em inovação na administração pública subnacional na década de 1990, Farah (1997:127) ressalta otimista que as iniciativas analisadas "respondem a demandas da sociedade brasileira, sugerindo um movimento de busca de superação tanto das práticas clientelistas e particularistas quanto da inércia burocrática".

Uma década mais tarde, revisão da bibliografia dos anos 2000 por Lima e Vargas (2012), seguida por Brandão e Bruno-Faria (2013), enfatiza que a produção científica quanto à inovação no setor público ainda se encontra limitada e que se faz necessário desenvolver mais conhecimento sobre a sua natureza. Entre suas principais conclusões os autores ressaltam: i) a inovação nos serviços públicos é pouco estudada; ii) no setor público é comum a adoção de inovações desenvolvidas pelo mercado; iii) deve ser realizada um distinção entre inovações em processos, ou em administração. Os autores propõem uma agenda de pesquisa à qual o presente artigo busca corresponder.

Visamos aqui, também, superar a desilusão enunciada por Flyvbjerg (2001) quanto à alegada incapacidade das ciências sociais - em oposição às exatas - em influir na gestão pública e, por decorrência, nos processos de desenvolvimento. Tópico que permeia o debate público:

As ciências econômicas, diferente das ciências naturais, raramente geram resultados definitivos. (...) Jornalistas, políticos e o público em geral, têm a tendência a atribuir ao que os economistas dizem uma autoridade e precisão maiores do que os próprios economistas deveriam realmente aceitar. (Rodrik, 2013:A13)

\section{Referencial teórico}

Uma distinção crucial entre a administração pública e a gestão empresarial reside no fato de o setor público deter a responsabilidade por tratar com problemas contraditórios, ou intratáveis. O conceito, no original wicked problems, foi proposto pelo pesquisador Horst Rittel nos anos 1960 (Churchman, 1967; Rittel e Webber, 1973). São aqueles problemas que caracterizam sistemas sociais abertos, que não podem ser tratados de forma cartesiana com enfoques do tipo PMI Handbook, pois: i) são problemas difíceis de identificar e descrever; ii) não possuem solução, pois dependem de que um grande número de pessoas mude seu comportamento; iii) 
estão em constante transformação por serem sintomas de problemas mais profundos; e iv) envolvem um elevado número de atores, cada um com seus interesses específicos e desejo de manutenção do seu poder, ou acesso a mais poder.

Por motivo de suas interconexões, o esforço pontual para solucionar um dos aspectos de um problema contraditório pode revelar, ou criar, novos problemas. Exemplos conhecidos: o tráfico de drogas e a violência a ele associada, as mudanças climáticas e a mobilidade urbana em grandes cidades. Para esses problemas não existe uma solução falso-verdadeiro, apenas tratamentos melhores ou piores por políticas públicas continuamente repetidas e repensadas. E não existe possibilidade de testar previamente políticas públicas para esses tipos de problema, pois o impacto de uma iniciativa somente pode ser avaliado após sua implementação, visando aprender com os erros.

Rittel e Webber (1973) propõem um modelo colaborativo, ou participativo, de administração pública para lidar com problemas contraditórios, visando envolver o maior número possível de atores no diálogo. Enfoque que tem sido a práxis na administração pública brasileira, por meio da formação de um grande número de fóruns, colegiados e conselhos setoriais nas três esferas do Estado, buscando encaminhar propostas e soluções para problemas contraditórios em nossa sociedade.

Coser (1956), porém, argumenta que conflitos sociais sobre problemas complexos não têm solução e, mais que isso, podem ter funções benéficas para a sociedade, p.ex., promovendo o ativo engajamento de grupos antes excluídos da vida pública, ou possibilitando uma coesão interna quando a sociedade precisa unir-se para enfrentar riscos. O autor enfatiza que o conflito social pode representar uma fonte de inovação e de avanço da gestão pública, pois novos problemas representam novos desafios, a serem tratados com novas ferramentas e novas instituições.

Nesse sentido, existe potencial para a ciência da administração em prover estudos, hoje frequentemente restritos a outras disciplinas das ciências sociais, acerca do contexto político que origina políticas públicas - em especial as inovações - no intuito de compreender as estruturas e os gestores que promovem a inovação subnacional. Em acordo com o enunciado de Sztompka (1998:14): "Uma das peças mais preciosas do saber sociológico é o princípio do historicismo. Ele diz que para se compreender qualquer fenômeno devemos pesquisar suas origens e processo de formação".

Além do conflito social do qual emergem novas utopias e demandas a serem atendidas pelo Estado para tratar de problemas contraditórios - conceito que já havia sido analisado pelo pensador Antonio Gramsci nos anos 1930 (Semeraro, 1999) —, ressaltamos ainda a existência do conflito entre a vontade dos eleitores, expressa no voto majoritário, e o plano de governo que acaba sendo possível pela equipe política eleita. Os estudos da administração empresarial dedicam amplo espaço ao conflito de agência, porém, a administração pública pouco tem se ocupado em analisar a existência ou não de causalidade entre o mandato conferido pelo eleitor e as políticas públicas daí resultantes.

Assim como nos estudos sobre o conflito de agência nas empresas, o estudo acerca da execução de um conjunto de políticas públicas em um governo subnacional representa uma 
análise acerca do poder. A forma pela qual um governo exerce poder, sua capacidade em priorizar, planejar, implementar ações e cumprir com o mandato conferido pelo eleitor. Resumido pelo conceito da boa governança. Nas palavras do ex-presidente Lula, um experiente gestor público: "É bom que a gente tenha problema para resolver, porque quanto mais problema você tem, mais você exerce a democracia. E quanto mais você resolve, mais forte fica" (Klein, 2013:A7).

Neste sentido, refletimos aqui sobre a atual estratégia de desenvolvimento do governo do Acre como estudo de caso de inovações que geraram a boa governança, selecionado por motivo de suas especificidades apresentadas a seguir.

\section{0 desafio}

O Acre ocupa posição diferenciada na geopolítica brasileira, dada sua localização na zona de transição entre a Amazônia Central e a planície das cabeceiras dos rios Juruá, Purus e Madeira aos pés da cordilheira dos Andes. Esta zona de transição confere ao Acre não apenas uma tipologia diferenciada de florestas, mas relevância no regime hídrico. Chuvas excessivas no Acre em fevereiro/março originam alagações no interior do estado do Amazonas em abril/ maio, seguidas por inundações no norte do Pará em junho/julho.

De acordo com pesquisas recentes (Arraut, 2008), ventos e nuvens oriundos do oceano Atlântico ingressam no continente sobre o litoral do Maranhão e do Pará, seguindo o curso da planície do rio Amazonas acumulando umidade. Sobre o Acre este "rio aéreo" faz uma curva rumo ao Sul, indo desaguar através de chuvas no Mato Grosso do Sul, Paraná, Paraguai e Noroeste da Argentina. Configura-se, assim, o Acre como um território diferenciado no que se refere aos padrões de hidrogeografia do país.

E sua geografia torna o estado especialmente vulnerável às mudanças do clima, tanto pela direção dos ventos e padrão de chuva, como por sua rede hidrográfica. Por estar situado na cabeceira das bacias hidrográficas, o Acre enfrenta fortes oscilações do nível dos rios ao longo do ano, tornando tanto o abastecimento residencial e industrial, bem como a logística no território, um desafio. O desmatamento na região altera o regime hídrico, a geomorfologia e a composição bioquímica dos rios, reduzindo a transpiração da superfície, aumentando o volume e a força da chuva sobre o solo, causando inundações, erosão e assoreamento dos rios (Coe et al., 2011).

Ampliando os riscos, no Sudoeste da Amazônia está previsto um dos maiores complexos de geração de energia em florestas tropicais, com impactos ainda imprevisíveis do desmatamento sobre o balanço hídrico da região (Stickler et al., 2013). Na bacia hidrográfica do Alto Rio Madeira/Madre de Dios está prevista a construção de cinco barragens, sendo planejados Inambari (2.200 MW) no Peru, a barragem de Cachuela Esperanza (990 MW) na Bolívia e a Binacional (3.000 MW) na fronteira entre Bolívia e Brasil. Em obras, Jirau (3.750 MW) e Santo Antônio (3.150 MW) em Rondônia.

As mudanças climáticas estão alterando o regime hídrico da Amazônia, influenciando economia e sociedade. No verão de 2005 (37\% do normal de chuvas) a Amazônia sofreu uma 
Seca do Século, gerando perda de 267 mil hectares de floresta por queimada no Acre, um prejuízo da ordem de R 33 bilhões em serviços ambientais (Brown, 2013b). Em 2010 ocorreu nova Seca do Século (57\% do normal de chuva) (Lewis et al., 2011; Sassan et al., 2013).

Em fevereiro de 2012 o Acre sofreu a Enchente do Século, as cidades de Brasileia e Rio Branco foram as mais atingidas, contando 7.800 desabrigados, e na região de Santa Rosa do Purus 17 aldeias indígenas ficaram submersas. Ao todo, 140 mil pessoas foram atingidas no estado, com danos estimados de R $\$ 134,5$ milhões a edificações e R $\$ 16,4$ milhões na economia (Moura, 2012). Com a perda das lavouras de mandioca, em meados de 2013 faltou o produto, e o preço da farinha de mandioca em Rio Branco explodiu de $\mathrm{R} \$ 70 /$ saca para R\$ 140/saca (Arruda, 2013:E1).

Entre enchentes e queimadas, os prejuízos econômicos e sociais ao Acre no período entre 2005 e 2012 são estimados em R 500 milhões (Oliveira, 2011; Brown, 2013b). Um peso elevado para um dos estados com menor arrecadação própria da federação.

De acordo com as projeções por Barbieri e Confalonieri (2008) acerca dos impactos das mudanças climáticas até 2050 no Brasil, os grupos mais vulneráveis da população irão sofrer os maiores efeitos. De forma simplificada, quanto maior o número de beneficiários das políticas de transferência de renda em uma comunidade, maior sua vulnerabilidade aos impactos do clima. O Acre conta com 70.900 famílias beneficiárias do programa Bolsa Família, algo como $40 \%$ da população total, ressaltando o elevado grau de vulnerabilidade social e econômica do território.

Quanto ao argumento de que esta seria uma realidade nova, ainda pouca estudada, de que ainda persistiriam imprecisões sobre o impacto das mudanças climáticas na Amazônia e, portanto, não haveria necessidade de políticas públicas, interessa o Decreto-Lei ํㅡ 8.843, de 1911, criando a primeira reserva florestal do país:

O Presidente da Republica dos Estados Unidos do Brazil, atendendo a que a devastação desordenada das mattas está produzindo em todo paiz efeitos sensíveis e desastrosos, salientando-se entre eles alterações na constituição climaterica de varias zonas e no regimen das aguas pluviaes, e reconhecendo que é da maior e mais urgente necessidade impedir que tal estado de cousa se estenda ao Territorio do Acre, decreta: Fica creada no Territorio do Acre a Reserva Florestal, uma faixa de $40 \mathrm{~km}$ de largura, sendo vedada a entrada. (...) Si existirem moradores, fica-lhes concedido o prazo de 12 mezes para exhibirem seus titulos de posse. (Brasil, 1911)

Uma versão atualizada deste alerta vem ocupando espaço na mídia:

Os temporais que sempre assustam São Paulo estão mais frequentes. É o que indica estudo feito por especialistas em climatologia da USP. Segundo os cientistas, o que mais deve preocupar os gestores públicos não é a quantidade de chuva. Mas, sim, a ocorrência cada vez maior das tempestades. Sem uma maior preparação para essas chuvas mais concentradas, a vulnerabilidade da capital vai crescer. (...) Entre 2000 e 2009 ocorreram 70 temporais fortes acima da média em São Paulo, nos anos 1970 foram 50 registros. (Geraque, 2013:C4) 
Assim, a especificidade de sua geografia, a fragilidade de sua economia dependente dos subsídios do setor público e a vulnerabilidade de larga parte de sua população tornam o estado do Acre especialmente suscetível aos eventos extremos e impactos das mudanças climáticas (Margulis, Dubeux e Marcovitch, 2011). Demandando, portanto, ações de mitigação e adaptação por parte do seu governo (Marengo et al., 2007).

Por último, dada a virtual ausência do Estado nos três territórios adjacentes: o Sudoeste do estado do Amazonas, a faixa norte do departamento de Pando na Bolívia e a fronteira leste da província de Ucayali no Peru, a organização administrativa e o desempenho do setor público acriano têm influência simbólica e política em uma região quase o dobro do tamanho de seu território.

\section{0 processo de inovação}

O governo do Acre estabeleceu ao longo da última década uma das mais abrangentes políticas de inclusão social e adaptação aos impactos das mudanças climáticas na Amazônia. Esta estratégia foi concebida sob o slogan de Florestania, nos anos 1990, depois passou a ser chamada de desenvolvimento regional sustentável nos anos 2000, atendendo aos critérios do que hoje é classificado como uma economia de baixo carbono. As denominações mudam de acordo com o amadurecimento do debate público, mas a estratégia desenhada pela gestão pública estadual vem tendo uma continuidade de 14 anos, rara no cenário nacional (Silva, 2011).

O processo de inovação foi gestado nos anos 1980, a partir dos movimentos sociais dos seringueiros que se opuseram à estratégia de desenvolvimento então predominante no estado. Seguindo a herança ibérica de ocupação do território pelo casco do gado, desde início dos anos 1970 o governo federal vinha atraindo pecuaristas da região Sudeste com vantagens na aquisição de terra e facilidades do crédito subsidiado para instalação de pastagens mediante derrubada da floresta. Essa política expulsou de modo particularmente violento a população da floresta, pois, ao contrário do que apregoava o marketing do governo militar, a floresta não era vazia. Silva (1981:117) classificou-a como: "uma doutrina de esvaziamento dos espaços ocupados". Levando algo como metade da população, as famílias extrativistas, à perda de seu modo de vida e sua autonomia, restando a opção de virar peão de gado nas novas fazendas, migrar para a periferia dos incipientes núcleos urbanos no estado ou fugir para as matas da Bolívia (Esteves, 2010; Pantoja, 2004).

A reação foi articulada por uma aliança entre os Sindicatos de Trabalhadores Rurais no Vale do Rio Acre, que desenvolveu a tecnologia social denominada empate, com grupos de famílias ocupando os varadouros, pacificamente impedindo o avanço das motosserras, tratores de esteira e desfolhantes químicos. Como reação, diversos sindicalistas foram assassinados. A violência que marcou o Acre naquele período demandou inovações para além da paralisação pontual do desmatamento.

O setor público buscou enquadrar os conflitos através das ferramentas da Política de Reforma Agrária, assentando seringueiros - acostumados ao manejo de centenas de hectares de 
mata nativa - em pequenos lotes retangulares nos assentamentos desenhados pelo Instituto Nacional de Colonização e Reforma Agrária (Incra) com régua no mapa, sem vinculação com o relevo ou a geografia das bacias hidrográficas que delineiam o modo de vida e de produção dos seringueiros, o que se mostrou pouco realista.

As lideranças dos movimentos sociais, por sua vez, buscavam adequar as políticas públicas às suas demandas, gerando inovações institucionais, como o Conselho Nacional dos Seringueiros e a Aliança dos Povos da Floresta. Entre seus maiores êxitos figura a concepção da Reserva Extrativista (Resex). A partir da implantação da Resex Chico Mendes no município de Xapuri em 1990, como estratégia de oposição à política de pecuarização e desmatamento, emergiu a necessidade por uma estratégia de desenvolvimento territorial que incorporasse o princípio da valorização da floresta em pé. Marcando uma geração de jovens intelectuais, técnicos, políticos e pesquisadores, que passaram a buscar inovações para este enfoque de desenvolvimento (Rodrigues, 1998; Menezes, 2011).

O próximo laboratório foi uma política de inclusão social para os migrantes da floresta nas zonas urbanas, iniciando na capital Rio Branco. A prefeitura da capital foi conquistada no voto pela Frente Popular (FPA), assumindo em janeiro de 1993 uma aliança entre movimentos sociais, grupos militantes, associações comunitárias e diversos partidos, que colocou na gestão municipal o jovem engenheiro florestal Jorge Viana, assessorado por uma equipe de militantes e técnicos. Essa administração inverteu a prioridade das políticas setoriais, saneando o orçamento público, promovendo a legalização e urbanização das vilas periféricas, privilegiando o transporte público, a universalização da educação e a qualidade do atendimento à saúde (Franca, 2009). O impacto positivo junto aos grupos sociais antes marginalizados foi de tal magnitude, que, em outubro de 1998, a plataforma de governo da FPA venceu as eleições para governador, fenômeno eleitoral que vem se repetindo desde então.

A política de desenvolvimento com inclusão social — denominada na época de Florestania — teve por base a elaboração de um Zoneamento Ecológico Econômico (ZEE) na escala 1:1 milhão para o estado, publicado em 2000. No período 2005-06 foi encaminhado abrangente número de estudos setoriais, bem como realizada consulta tanto a especialistas como a um número significativo de comunidades, gerando uma segunda versão, mais detalhada na escala 1:250 mil e regulamentada em 2007 (Acre, 2006). Foram definidas quatro zonas de intervenção no estado:

Zona 1 - Consolidação de sistemas de produção (pecuária, agricultura, reflorestamento) em áreas já desmatadas (cerca de $25 \%$ do território);

Zona 2 - Uso sustentável dos recursos naturais e proteção ambiental em unidades de conservação, terras indígenas e projetos de assentamento diferenciados (cerca de 46\% do território);

Zona 3 - Áreas remotas, de posse conflituosa, prioritárias para ordenamento territorial (cerca de $25 \%$ do território); e

Zona 4 - Áreas urbanas.

Cada zona é subdividida em subzonas, com diretrizes específicas para o planejamento e uso do território. Foram definidas cinco Zonas Especiais de Desenvolvimento (ZED) para 
focalizar o fomento econômico, além de Zonas de Atendimento Prioritário (ZAP) englobando 1.982 comunidades urbanas e rurais. Nas ZAP é realizado um processo de elaboração participativa de planos comunitários, que consolidam as demandas nas áreas de educação, saúde e assistência social, direcionando as políticas públicas (Acre, 2010). Uma tipologia da gestão pública na Amazônia ainda sem similar.

No sentido de nortear as intervenções nas Zonas 1 a 3, foi estabelecida a Política Estadual de Valorização do Ativo Ambiental (Acre, 2008). Essa política, como principal mecanismo de implementação do ZEE, prevê um conjunto integrado de políticas públicas ordenadas em dois eixos, o Programa de Recuperação de Áreas Degradadas e o Programa do Ativo Florestal. Iniciativas setoriais foram integradas, consolidando o impacto dos projetos. Por exemplo, a criação do Instituto de Terras do Acre (Iteracre), sua integração com Incra e Instituto de Meio Ambiente (Imac), possibilitou a rápida expansão da regularização fundiária e do licenciamento ambiental no estado. Na Fundação de Tecnologia foi criada a Unidade de Geoprocessamento, dotada de equipamentos de georreferenciamento e capacidade para produção de mapas no estado da arte. O projeto de Pagamento por Serviços Ambientais mereceu legislação específica em 2010, a lei do Sisa, colocando o Acre na vanguarda mundial deste setor.

Mediante este enfoque integrado, que cobre desde emissão de títulos e controle de queimadas até projetos de fomento à comercialização em cadeias produtivas selecionadas (Acre, 2011; Acre, 2012a), a política combina mecanismos de controle do território com ferramentas do fomento econômico (Acre, 2009), desta forma reduzindo o deslocamento populacional e, consequentemente, a pressão sobre a mata em pé (Adeodato, 2011).

Tendo em vista a limitada capacidade da iniciativa privada em gerar conhecimento e inovações desta amplitude, a gestão de conhecimento para esta política tem origem na gestão pública e organizações da sociedade civil. Em especial, nos projetos-piloto do Parque Zoobotânico da Universidade Federal do Acre nos anos 1990, onde foram formados diversos dos futuros técnicos e dirigentes públicos, atuando em interação com a Embrapa-AC (De Deus et al., 1993; Brooke e Witoshynsky, 2002; Rodrigues et al., 2004).

Desta forma, a administração pública logrou consolidar ao longo de uma década o controle sobre o território, fato raro na Amazônia, e está em condições de direcionar as atividades dos agentes econômicos de forma a possibilitar a ocupação das bacias hidrográficas de modo racional, contribuindo para a recuperação da capacidade de produção de água potável no território.

A capital Rio Branco e seu entorno somam 50\% da população do estado e representam, portanto, o foco e o laboratório das políticas de adaptação às mudanças do clima no contexto urbano. Entre as iniciativas que merecem destaque:

- Polos Agroflorestais, assentamentos periurbanos com lotes de um a três hectares cada, evitando que famílias migrantes ocupem áreas de risco;

- Realocação de famílias retiradas de áreas de risco, iniciada com reurbanização da orla do rio Acre, seguida de integração com o programa federal Minha Casa, Minha Vida para criar reassentamento de 3.300 famílias; 
、 Após remoção das famílias das áreas de inundação, desobstrução das margens de igarapés, criando áreas de lazer e parques lineares com ciclovias, além de projetos de recuperação de matas ciliares;

จ Prevenção da impermeabilização das áreas urbanas mediante calçamento das ruas com tijolos, através do programa Ruas do Povo;

v Criação do Programa Municipal de Arborização Urbana, buscando planejar e sistematizar a arborização nas cidades.

Entre as inovações recentes, merecem destaque, ainda, a elaboração do primeiro inventário estadual de emissões de gases de efeito estufa na Amazônia (Brasil, 2012), além da elaboração do Plano Estadual de Recursos Hídricos através de consulta à sociedade civil (Acre, 2012b).

Além do desenvolvimento rural e das políticas urbanas, como terceiro elemento deste tripé de adaptação às mudanças climáticas, ressaltamos a contínua ampliação da capacidade de prevenção de desastres através da qualificação profissional e da interação entre Polícia Militar, Bombeiros e Defesa Civil. Em pesquisa encomendada pelo Ministério da Justiça em 2012, a Polícia Militar do Acre figurava entre as três mais confiáveis em toda a federação (Brasil, 2013).

A título de comparação, no estado do Rio de Janeiro, a segunda maior economia do país pelos royalties do petróleo (Monié e Binsztok, 2012), a catástrofe das enxurradas na Região Serrana repetiu-se em sequência em 1988 (134 mortes), 2011 (916 mortes) e 2013 (33 mortes), além da tragédia em 2010 em Angra dos Reis (53 mortes), evidenciando o descaso e o despreparo das administrações municipais e do governo estadual.

Em contraste, no Acre, com base no aprendizado em enchentes anteriores (Oliveira, 2011), na histórica enchente de fevereiro de 2012, que atingiu cerca de 140 mil pessoas, o governo estadual e as oito administrações municipais em estado de emergência demonstraram capacidade de articulação:

v abrigos rapidamente instalados atendendo critérios internacionais de qualidade da ajuda humanitária, possibilitando privacidade para mulheres e meninas;

、 as famílias desabrigadas tiveram permanente acesso a água potável e instalações para higiene pessoal, não ocorreu falta de alimentos;

v ocorreu amplo engajamento de servidores municipais e estaduais, sem sobreposição ou paralelismo, para além do horário regular de trabalho, na preparação de alimentos, distribuição de vestuário e doações a abrigados, além de recreação para as crianças;

v tanto governador como prefeitos das cidades atingidas estiveram diariamente presentes nas áreas alagadas e abrigos, respondendo perguntas, aferindo a qualidade dos serviços;

v o Ministério Público Estadual instalou escritório na área dos abrigos, para atendimento continuado, em especial, a mulheres vítimas de violência doméstica; 
- após a enchente, a remoção do entulho e a limpeza urbana nos bairros afetados foram realizadas de forma rápida e eficiente; o retorno das famílias às suas habitações ocorreu de forma planejada sob coordenação da Defesa Civil;

- não foram constatados casos de desvio ou abuso financeiro, seja dos recursos públicos ou das doações privadas, que foram canalizadas através de igrejas e suas instituições beneficentes.

O cenário repetiu-se em início de 2013, quando antes de chegar o auge das chuvas em final de janeiro, a Defesa Civil já havia instalado preventivamente mais de 50 abrigos. Foi realizada capacitação para radioamadores voluntários. Em março foi necessário prover abrigo para 1.610 pessoas, das quais 678 crianças. Em abril foi criado o Centro de Monitoramento de Eventos Climáticos, recebendo dados de 25 unidades de medição de volume dos rios no estado. E esta experiência tem impactos na região:

As chuvas de 2012 inundaram não só cidades acreanas, mas também as cidades de Cobija na Bolívia, e Iñapari no Peru. (...) As agências governamentais de Madre de Dios, Pando e Acre realizaram uma série de encontros para desenvolver sistema de informativos e alertas. (...) A Secretaria de Educação de Pando fez uma análise de vulnerabilidade das suas escolas e população estudantil, e estabeleceu uma sala de situação (...). Os meteorologistas de Cobija apresentaram como estão fazendo suas análises, que foram aprimoradas após terem participado de recente capacitação no Acre. (Brown, 2013a:2)

Este exemplo visa ressaltar a capacidade do setor público no Acre de prevenir e se preparar para o imponderável: eventos extremos e impactos das mudanças climáticas. Ao mesmo tempo que, p.ex., o governador do Rio de Janeiro utiliza a justificativa do imponderável para explicar o aumento em quase $90 \%$ no custo final da obra de reforma do estádio do Maracanã (Konchinski, 2013).

\section{Reflexões}

Existem diversos ângulos possíveis para uma interpretação da estratégia do setor público para o desenvolvimento no Acre. Retomando a análise de Farah (1997), podemos argumentar que seu otimismo era justificado e que, na experiência de mais de uma década de redemocratização no Acre, foi possível construir um novo Estado, ao mesmo tempo mais democrático e mais eficiente com a remoção do entulho autoritário remanescente da ditadura e do coronelismo, tornando o setor público mais permeável às exigências e à dinâmica da sociedade civil.

Nos anos 1970, deter o avanço da barbárie da pecuarização na Amazônia era uma utopia (Silva, 1981). Hoje em dia, acostumada a 25 anos de democracia e com vaga lembrança sobre o desafio da redemocratização, possivelmente a opinião pública dará pouco valor a 
este ponto de vista. Porém, perante o fracasso do governo federal em promover o desenvolvimento subnacional no Nordeste (Sampaio, 1979), a estratégia do desenvolvimento endógeno do Acre não deve ser subestimada. O jovem acriano incorporou às perspectivas de sua vida a garantia de direitos, a possibilidade de ascensão social e, sobretudo, uma vida sem fome, experiência comum a muitos dos seus pais nos anos 1970-80:

Eu acordava quatro horas da madrugada, eu cortava seringa, chegava (em casa) e ia pro roçado cuidar dos legumes. (...) Quando eu chegava, as outras crianças mais pequenas ia colher mais os meninos, e eu ia pro roçado trabalhar, capinar, plantar um arroz, plantar feijão até cinco horas da tarde. (...) Meu patrão (no seringal) era chamado Zé da Silva. Passava fome, muita fome, a gente passava (...). Pra vestir os filhos, a gente ia pelejando, vendia uma galinha, vendia um porquinho. (depoimento sobre o seringal nos anos 1970, coletado por Souza, 2010:40)

No Acre atual, a maioria dos jovens terá a oportunidade de dar a seus filhos uma infância melhor do que a sua. Que outro descritor melhor para explicitar a importância da democracia e do estado de direito?

Sob um ângulo diferente, de acordo com as metas definidas para a década passada pelo Conselho Nacional do Desenvolvimento Rural Sustentável, quando se propagava o conceito do Novo Rural (IEA/USP, 2001):

O rural é necessariamente territorial, e não setorial como os programas dos órgãos governamentais. O grande desafio está, portanto, em adotar uma orientação realista que possa viabilizar uma transição factível de ações setoriais para uma articulação horizontal das intervenções, para ajudar as microrregiões rurais a garantir bem-estar e cidadania. (Brasil, 2002:8)

Podemos argumentar que no Acre - um estado com baixa densidade populacional, assim, pelos padrões internacionais, um estado rural — foi concretizado um plano de governo para o desenvolvimento rural sustentável. Nenhum outro estado da Amazônia reduziu tanto o desmatamento ilegal na última década, ao mesmo tempo registrando aumento da produção e produtividade agropecuária, diversificação da renda e crescimento populacional. Como o termo rural possui, ainda, um viés pejorativo, possivelmente não seja o melhor slogan para divulgar um plano de governo. Porém, merece registro o impacto positivo da administração pública acriana, enquanto relatório de avaliação interna aponta que ao longo da mesma década o Banco Mundial não logrou integrar crescimento econômico, proteção ambiental e inclusão social nos 345 projetos florestais financiados em 75 países (World Bank, 2012).

Nos anos 1990 foi cunhado pelos movimentos sociais do Acre o conceito de Florestania, um slogan que contribui para sintetizar a estratégia de reverter as prioridades do setor público focadas na pecuarização do estado, e estabelecer políticas públicas de inclusão social. Na clássica concepção de Marshall (1967), a garantia dos direitos civis, políticos e sociais. Florestania foi um conceito de aceitação popular, vencedor de quatro eleições e que foi cumprido entre 1992 e 2012. 
A terceira etapa, ora em curso, representa na verdade o maior desafio ao setor público, pois implica a inclusão produtiva das famílias, para além da assistência social. Por definição, dependente de ações de longo prazo, na qual o setor público em geral tem baixa eficácia. Em uma década não é possível atender a todas as expectativas e anseios acumulados em um século de omissão do Estado em uma frente pioneira como o Acre, levando a frustrações e a um desgaste do termo Florestania. O que é coerente com o conceito dos problemas contraditórios, pois na medida em que um ator intervém sobre um problema, novos surgem. Não existe uma solução. Neste sentido, o desgaste da atual equipe política constitui novo problema que emerge. Assim como outros problemas têm surgido, por exemplo, a cobrança pelos partidos da oposição de que o Acre não deveria seguir um modelo próprio, mas copiar o modelo de Rondônia. Novos problemas complexos demandam novas soluções e novas instituições públicas.

Independentemente da tipologia a ser utilizada para classificar e analisar o caso da estratégia de desenvolvimento no Acre, podemos argumentar tratar-se de um caso exitoso de políticas públicas colocadas a serviço da maioria dos cidadãos, possibilitando minimizar a miséria e promover a inclusão social.

A inovação em governança, ou a origem e formatação de planos de governo, representa, porém, um campo pouco afeito à pesquisa pela administração, tendo em vista sua caracterização difusa como intersecção entre elementos ideológicos, culturais e partidários, dificilmente quantificáveis. A origem, composição e preferência dos planos de governo vencedores na eleição têm sido um objeto de análise preferencial para os estudos da sociologia política.

A avaliação de planos de governo é realizada - de forma objetiva e subjetiva - pelo eleitor, ao expressar sua preferência por meio do voto por uma equipe de políticos para uma das plataformas apresentadas na campanha eleitoral. O voto, por sua vez, como expressão concreta da subjetividade da escolha pelo cidadão, é objeto de estudo da ciência política. Em geral, porém, sem entrar nos méritos do conteúdo do plano de governo selecionado através da eleição (Borba, 2005).

Os impactos e as consequências das políticas públicas definidas por uma equipe de governo, bem como sua racionalidade e viabilidade, são frequente objeto de estudo pela economia, formando a base para a gestão de conhecimento que tem enriquecido e diversificado a gestão pública.

Os estudos da administração detêm o potencial de analisar a intersecção destas disciplinas, visando compreender, por um lado, se existe correspondência entre a vontade expressa pelo eleitor durante a campanha eleitoral e o plano de governo adotado, e, por outro lado, se o conjunto das políticas públicas corresponde ao plano de governo (Olivieri, 2011).

Buscamos reforçar este argumento com o presente estudo de caso, ressaltando que, para entender a alta qualidade da governança no Acre, evidenciada, por exemplo, pelo excepcional desempenho da estratégia de atendimento à população na enchente de fevereiro de 2012, em contraste com os inadequados serviços prestados pela administração pública do Rio de Janeiro no atendimento das enxurradas na Região Serrana, não basta estudar apenas a estrutura da Defesa Civil do Acre. A atual capacidade e profissionalismo da Polícia Civil, 
Bombeiros e Defesa Civil no Acre foi alcançada mediante uso de técnicas e ferramentas da administração pública, tornado possível pelo enfoque de boa governança, que, por sua vez, tem raiz na cultura e na sociedade do estado. Colocado em linguagem coloquial:

Desconfie, leitor, quando ouvir alguém dizer que certo procedimento "não resolve" um problema da sociedade. Duvide, também, quando topar com a assertiva oposta: se adotássemos a medida tal, solucionaríamos o problema. O mito da bala de prata aparece bastante no debate econômico. Para certo time de desenvolvimentistas, basta manter desvalorizado o Real para que tudo se ajuste. Do outro lado estão os fanáticos pela liberdade total dos mercados. São mais vantajosas as abordagens incrementais, que levam em conta mais de um aspecto do problema e visam à sua melhoria no tempo — nem sempre à solução. (Mota, 2013)

O bom desempenho técnico, a capacidade de integração entre a esfera estadual e municipal, o respeito pelo cidadão e a ausência de desvio de verbas observada no atendimento a emergências no Acre representam o produto de uma política de desenvolvimento com continuidade desde 1999, permitindo a gestão de conhecimento e o contínuo aperfeiçoamento da burocracia estadual. E sua concepção inicial, por sua vez, tem origem na utopia gerada pelos movimentos sociais e demais organizações da sociedade civil nos anos 1980 (Bezerra, 2006). Em outras palavras, constata-se um alinhamento entre o mandato dado pelo eleitor através do voto, a plataforma política que administra o território com base nos potenciais e limitações dos recursos disponíveis, e os resultados obtidos pelas políticas públicas. Fenômeno raro na gestão pública brasileira e que vem reduzindo - lenta e gradualmente - a vulnerabilidade do Acre aos impactos das mudanças climáticas.

O resultado da estratégia de desenvolvimento em vigor no Acre está de acordo não apenas com o mandato da maioria dos eleitores como corresponde à demanda pelas organizações da sociedade civil nacional para adaptação às mudanças do clima (Fórum, 2009). Também atende ao Relatório Especial sobre Riscos de Eventos Extremos do Painel Intergovernamental sobre Mudanças Climáticas (IPCC, 2012), que recomenda um processo gradual de ação e aprendizado pelo setor público para reduzir as vulnerabilidades e prevenir os impactos de desastres.

O estudo da atual estratégia de desenvolvimento do Acre permite, além disso, verificar pontos de intersecção entre as ciências sociais e a burocracia pública (para o caso da Califórnia, veja Franco et al., 2008). Profissionais de diversas áreas das ciências sociais assessoraram nos anos 1980 lideranças de movimentos sociais e comunidades de base, transformando suas demandas em projetos e iniciativas-piloto que, posteriormente, foram levados ao cerne do governo quando estes profissionais passaram a fazer parte da administração pública (para o caso do México, veja Chand, 2001). Ali, estas utopias e anseios tornaram-se políticas públicas, com base em significativo número de estudos encomendados a instituições de pesquisa e ensino (para o caso da África do Sul, veja Barberton, Blake e Kotzé, 1988). Contribuindo para a definição de novas organizações estatais criadas nos anos 1990 (p.ex., Iteracre) e nos anos 2000 (p.ex., Instituto de Mudanças Climáticas — IMC). 
Uma das perguntas centrais para estudos futuros reside na origem e formação dos gestores públicos do Acre. Estes não cursaram escolas de governo, nem receberam formação em administração pública. A análise das raízes de seu engajamento e comprometimento com a causa pública poderia oferecer sugestões para o currículo de cursos e capacitações direcionadas a preparar a próxima geração de gestores públicos (para um esboço, veja sobreposição entre Klein, 2009, e Fernández, 2012). Pois, com a crescente complexidade da sociedade e a tendência de surgimento de novos problemas contraditórios, a longo prazo o bom senso e uma formação generalista não serão mais suficientes para a boa governança. Demandando uma preparação mais profissionalizada, para além do enfoque no direito público que hoje ainda marca muito da educação em administração pública.

\section{Referências}

ACRE. Governo do Estado. Política de valorização do ativo ambiental florestal: manual operativo. Rio Branco, 2008.

ACRE. Governo do Estado. Zoneamento ecológico-econômico do Acre. Fase II. Documento síntese. Rio Branco: Sema, 2006.

ACRE. Plano estadual de prevenção e controle do desmatamento. Rio Branco: Sema, 2010.

ACRE. Programa ZEE. Alternativas de utilização de áreas alteradas no estado do Acre. Rio Branco: Sema, 2011.

ACRE. Rede de Extensão Agroflorestal. Princípios, diretrizes, critérios e instruções: credenciamento da rede de Ater para certificação da Unidade de Produção Sustentável. Rio Branco: Seaprof, 2009.

ACRE. Secretaria de Meio Ambiente. Plano estadual de recursos hídricos. Rio Branco: Sema/WWF/ GIZ, 2012b.

ACRE. Secretaria de Meio Ambiente. Uso sustentável de ecossistemas de pastagens cultivadas na Amazônia Ocidental. Rio Branco, 2012a.

ADEODATO, Sérgio et al. Madeira de ponta a ponta: o caminho desde a floresta até o consumo. São Paulo: FGV EAESP/WWF/Defra, 2011.

ARRAUT, Josefina. Frentes e frontogêneses no verão: aspectos geométricos, dinâmicos e impactos sobre as chuvas nos Subtrópicos da América do Sul. Inpe-15178-TDI/1294. São José dos Campos: Inpe, 2008.

ARRUDA, Itaan. Preço do custo da farinha aumenta 100\% nos últimos três meses. A Gazeta, Rio Branco, 6 maio 2013. Acre Economia, p. 1.

BARBERTON, Conrad; BLAKE, Michael; KOTZÉ, Hernien. Creating action space: the challenge of poverty and democracy in South Africa. Cape Town: Idasa, 1988. 
BARBIERI, Alisson; CONFALONIERI, Ulisses (Coord.). Mudanças climáticas, migrações e saúde: cenários para o Nordeste, 2000 a 2050. Belo Horizonte: UFMG; Rio de Janeiro: Fiocruz, 2008.

BEZERRA, Maria. Invenções do Acre: de território a estado - um olhar social. Tese (doutorado) - Pós-Graduação em História Social, Pontifícia Universidade Católica de São Paulo, São Paulo, 2006.

BORBA, Julian. Cultura política, ideologia e comportamento eleitoral: alguns apontamentos teóricos sobre o caso brasileiro. Revista Opinião Pública, v. 11, n. 1, p. 147-168, mar. 2005.

BRANDÃO, Soraya; BRUNO-FARIA, Maria. Inovação no setor público: análise da produção científica em periódicos nacionais e internacionais da área de administração. Rev. Adm. Pública, v. 47, n. 1, p. 227-248, jan./fev. 2013.

BRASIL. Conselho Nacional de Desenvolvimento Rural Sustentável. Plano para o desenvolvimento sustentável do Brasil rural. 1a versão do PNDRS. Brasília, jun. 2002.

BRASIL. Embrapa Acre. Inventário de emissões antrópicas e sumidouros de gases de efeito estufa do estado do Acre: ano base 2010. Rio Branco: Embrapa/IMC, 2012.

BRASIL. Ministério da Justiça. Pesquisa nacional de vitimização. Datafolha. Brasília: Pnud, 2013.

BRASIL. Senado Federal. Decreto no 8.843 de 26 de julho de 1911: Crêa a reserva florestal do Territorio do Acre - Presidente Hermes da Fonseca. Brasília: Subsecretaria de Informações, 1911.

BROOKE, Nigel; WITOSHYNSKY, Mary (Org.). OS 40 anos da Fundação Ford no Brasil: uma parceria para a mudança social. São Paulo: Edusp, 2002.

BROWN, Foster. Observaciones de que está ocurriendo en la Amazonia Sur-occidental. In: PANEL INTERNACIONAL DE AMBIENTE Y ENERGÍA EN LA AMAZONÍA, 2013, Bogotá. 2013b.

BROWN, Foster. Preparação transfronteiriça para desastres: Mini MAP Gestão de Risco e Defesa Civil. Jornal A Gazeta, Rio Branco, 24 fev. 2013a. p. 2.

CHAND, Vikram. Mexico's political awakening. Notre Dame: University of Notre Dame Press, 2001.

CHURCHMAN, Carl. Guest editorial: wicked problems. Management Science, v. 14, n. 4, p. B141B142, dez. 1967.

COE, Michael et al. The effects of deforestation and climate variability on the streamflow of the Araguaia river. Biogeochemistry, v. 105, n. 1-3, p. 119-131, fev. 2011.

COSER, Lewis. The functions of social conflict: an examination of the concept of social conflict and its use in empirical research. Nova York: Free Press, 1956.

DE DEUS, Carlos et al. Comportamento de 28 espécies arbóreas tropicais sob diferentes regimes de luz em Rio Branco. Rio Branco: Ufac; Fundação Ford, 1993.

ESTEVES, Benedita. Do 'manso' ao guardião da floresta: estudo do processo de transformação social do sistema seringal, a partir do caso da Reserva Extrativista Chico Mendes. Rio Branco: Edufac, 2010. 
FARAH, Marta. Gestão pública e cidadania: iniciativas inovadoras na administração subnacional no Brasil. Rev. Adm. Pública, v. 31, n. 4, p. 126-156, jul./ago. 1997.

FERNÁNDEZ, Joaquín. Primórdios de uma diocese: diocese de Rio Branco, 1986. Rio Branco: Francarlos, 2012.

FLYVBJERG, Bent. Making social science matter: why social inquiry fails and how it can succeed again. Cambridge: Cambridge University Press, 2001.

FÓRUM MUDANÇAS CLIMÁTICAS E JUSTIÇA SOCIAL. Mudanças climáticas e lutas pela vida: o que fazer? Taguatinga-DF: CNBB; Editora da Universidade Católica de Brasília, 2009.

FRANCA, Soad. A expansão da fronteira acreana. Brasília: Dupligráfica, 2009.

FRANCO, Guido et al. Linking climate change science with policy in California. Climatic Change, v. 87, n. Supplement Issue 1, p. S7-S20, mar. 2008.

GERAQUE, Eduardo. Temporais estão cada vez mais frequentes na capital. Folha de S.Paulo, 16 fev. 2013. Cotidiano, p. C4.

INSTITUTO DE ESTUDOS AVANÇADOS - IEA/USP. Dossiê desenvolvimento rural. Revista de Estudos Avançados, v. 15, n. 43, set./dez. 2001.

IPCC. Managing the risks of extreme events and disasters to advance climate change adaptation. Special report. Cambridge: Cambridge University Press, 2012.

KLEIN, Cristian. Lula expõe diferença com sucessora em livro sobre governos do PT. Valor Econômico, São Paulo, 13 maio 2013. p. A7.

KLEIN, Estanislau. O aprendizado de lideranças no contexto de comunidades do Acre onde houve sintonia com a Teologia da Libertação. In: BROSE, M. (Org.). Lideranças para a democracia participativa. Goiânia: Universidade Católica, 2009. p. 175-186.

KONCHINSKI, Vinicius. Governador liga aumento de 87\% do custo do Maracanã ao 'imponderável'. Folha de S.Paulo, 8 maio 2013. p. C2.

LEWIS, Simon et al. The 2010 Amazon drought. Science, v. 331, n. 6017, p. 554-568, fev. 2011.

LIMA, Dagmar; VARGAS, Eduardo. Estudos internacionais sobre inovação no setor público: como a teoria da inovação em serviços pode contribuir? Rev. Adm. Pública, v. 46, n. 2, p. 385-401, mar./ abr. 2012.

MARENGO, Jorge et al. Caracterização do clima atual e definição das alterações climáticas para o território brasileiro ao longo do século XXI. Sumário técnico. Brasília: MMA, 2007.

MARGULIS, Sergio; DUBEUX, Carolina; MARCOVITCH, Jacques (Org.). Economia da mudança do clima no Brasil. Rio de Janeiro: Synergia, 2011.

MARSHALL, Thomas. Cidadania, classe social e status. Rio de Janeiro: Zahar, 1967. 
MENEZES, Thereza. Reservas extrativistas no Amazonas: gênese, metamorfoses e efeitos sociais. In: SAUER, Sérgio; ALMEIDA, Wellington (Org.). Terras e territórios na Amazônia. Brasília: Editora UnB; Ford Foundation, 2011. p. 345-361.

MONIÉ, Frédéric; BINSZTOK, Jacob (Org.). Geografia e geopolítica do petróleo. Rio de Janeiro: Mauad X, 2012.

MOTA, Vinicius. Bala de prata. Folha de S.Paulo, 4 fev. 2013. Colunistas, p. 2.

MOURA, Anne. Comércio acreano começa a contabilizar danos após enchente. O Rio Branco, Rio Branco, 7 mar. 2012. p. A4.

OLIVEIRA, Regiani. Famílias afetadas por desastres relacionados à chuva na cidade de Rio Branco Acre: uma análise socioespacial. Dissertação (mestrado) — Pós-Graduação em Desenvolvimento Regional, Universidade Federal do Acre, Rio Branco, 2011.

OLIVIERI, Cecília. Os controles políticos sobre a burocracia. Rev. Adm. Pública, v. 45, n. 5, p. 13951424, set./out. 2011.

PANTOJA, Mariana. Os Milton: cem anos de história nos seringais. Recife: Massangana, 2004.

RITTEL, Horst; WEBBER, Melvin. Dilemmas in a general theory of planning. Policy Sciences, v. 4, n. 1, p. 155-169, 1973.

RODRIGUES, Ecio (Org.). Experiências coerentes para um Acre sustentável. Cadernos Certas Ações. Rio Branco: CTA, 1998.

RODRIGUES, Flavio et al. Os Apurinãs e as agroflorestas: uma experiência de educação indígena. In: BROSE, M. (Org.). Participação na extensão rural. Porto Alegre: Tomo, 2004. p. 151-161.

RODRIK, Dani. Para que servem os economistas? Valor Econômico, São Paulo, 13 maio 2013. Colunistas, p. A13.

SAMPAIO, Yony; GOMES, Gustavo; IRMÃO, José. Política agrícola no Nordeste: intenções e resultados, 1970-1979. Estudos sobre o Desenvolvimento Agrícola, n. 11. Brasília: Ministério da Agricultura, 1979.

SASSAN, Saatchin et al. Persistent effects of a severe drought on Amazonian forest canopy. Proceedings of the National Academy of Sciences, v. 110, n. 2, p. 565-570, jan. 2013.

SEMERARO, Giovanni. Gramsci e a sociedade civil: cultura e educação para a democracia. Petrópolis: Vozes, 1999.

SILVA, José. A modernização dolorosa: estrutura agrária, fronteira agrícola e trabalhadores rurais no Brasil. Rio de Janeiro: Zahar Editores, 1981.

SILVA, Mauro. Razões da sustentabilidade do Governo da Floresta: uma releitura do processo de desenvolvimento do estado do Acre. Tese (doutorado) — Pós-Graduação em Ciências Sociais, Universidade Federal Rural do Rio de Janeiro, Seropédica, 2011.

SOUZA, Carlos. Aquirianas: mulheres da floresta na história do Acre. Rio Branco: Instituto Envira, 2010. 
STICKLER, Claudia et al. Dependence of hdyropower energy generation on forests in the Amazon Basin at local and regional scales. PNAS Early Edition, v. 110, n. 23, p. 9601-9606, maio 2013.

SZTOMPKA, Piotr. A sociologia da mudança social. Rio de Janeiro: Civilização Brasileira, 1998.

WORLD BANK. Independent Evaluation Group - IEG. Managing forest resources for sustainable development. Washington, dez. 2012.

Markus Erwin Brose é doutor em sociologia política, pesquisador independente. E-mail: mbrose@uol. com.br. 